\title{
Analysis of Wildlife Tourism Experiences with Endangered Species: An Exploratory Study of Encounters with Giant Pandas in Chengdu, China
}

\begin{abstract}
This research study examined wildlife tourism experiences in a unique place and species combination; giant pandas at the Chengdu Research Base for Giant Panda Breeding (CRBGPB) in Sichuan, China. Content analysis was done on tourist reviews of CRBGPB on TripAdvisor.com in early 2012. The thematic analysis qualitative method was adopted in examining tourists' written reviews of experiences interacting with giant pandas. ROST CM6 and NVivo 8 were used for the content analysis and qualitative coding.
\end{abstract}

A variety of tourist experiences, motivations, and preferences were revealed. Although tourists' experiences were varied, satisfaction increased with closer encounters and interactions with the giant pandas. The thematic analysis identified three features of the wildlife tourism experiences at CRBGPB; tourists, giant pandas, and settings. Implications and management recommendations were identified for places offering wildlife tourism experiences.

Keywords: China; content analysis; wildlife tourism; giant panda; tourist experiences; thematic analysis; visitor-wildlife interaction; TripAdvisor.com

\section{Growth and challenges of wildlife tourism}

There is increased demand from tourists to interact with wildlife and especially with animals that are unusual or endangered (Shackley, 1996; Semeniuk, Haider, Cooper, \& Rothley, 2010; Rodger, Moore, \& Newsome, 2007). This growing worldwide demand to interact with wildlife has led to the emergence of a wide range of wildlife tourism activities (Semeniuk et al., 2010). It is estimated that there are 12 million wildlife tourism trips annually, with a growth rate of around $10 \%$ per year (Curtin, 2010). Paralleling the growth in wildlife tourism is the expanding demand for closer interactions with wildlife in their natural habitats (Rodger, Moore, \& Newsome, 2009).

Tourism can provide the economic rationale for the long-term conservation of endangered and rare species (Reynolds \& Braithwaite, 2001; Newsome, Dowling, \& Moore, 2004; Higginbottom, 2004), and result in the creation or continued existence of protected area integrated conservation and development projects (Johannesen \& Skonhoft, 2005).Wildlife tourism is regarded as a minimum impact activity and wildlife viewing is described as a non-consumptive use of wildlife (Duffus \& Dearden, 1990; Green and Higginbottom, 2001). However, there is no denying that wildlife tourism has had some negative effects on wildlife and their habitats. Several research studies have documented the negative impacts from tourist-wildlife interactions 
(Ballantyne, Packer, \& Falk, 2011; Orams, 2002; Higham \& Carr, 2003; Curtin, 2010). In contrast, other research has demonstrated the positive impacts of wildlife tourism on visitors' environmental knowledge and attitudes (Ballantyne, Packer, \& Hughes 2009; Ballantyne, Packer, \& Sutherland, 2011; Lee \& Moscardo, 2005).

A major challenge to wildlife managers is providing tourists with opportunities to observe rare or endangered wildlife while also protecting the species from deleterious impacts (Sorice, Shafer, \& Ditton, 2005; Ballantyne, Packer, \& Sutherland, 2011; Smith, Ham, \& Weiler, 2011). People have had close relationships with animals throughout history (Orams, 2002).Wildlife interactions (observing, feeding, touching, photographing or otherwise experiencing wild animals) occur in a wide variety of settings worldwide. Interactions with wildlife have become increasingly less destructive and more focused on observing, feeding, touching, swimming with, and photographing animals in their natural habitats (Duffus \& Dearden, 1990; Green \& Higginbottom, 2001; Knight, 2010; Orams, 2002; Rodger \& Moore, 2004). However, the importance of these interactions to the tourism sector and their impacts on many species of wildlife is not yet well understood. The interfaces between tourists (social) and wildlife (environmental) can make a critical contribution to the sustainability of tourism (Rodger \& Moore, 2004; Rodger et al., 2007). The key to sustainable development is the management of tourists, not the animals (Rodger \& Moore, 2004). Therefore, it is vital to develop an in-depth understanding of tourist experiences. Wildlife tourism aims to educate visitors about the threats facing wildlife and the initiatives required to protect the environment and maintain biodiversity (Ballantyne, Packer, \& Falk, 2011; Ballantyne, Packer, \& Sutherland, 2011). It also has been recognised that an increased understanding of tourist-wildlife interactions will contribute to the sustainability of wildlife tourism experiences (Rodger \& Moore, 2004).

\section{Previous research on wildlife tourism experiences}

There have been many valuable contributions to the general literature on tourist experiences (Ryan, 2002; Pike \& Ryan, 2004; Quan \& Wang, 2004; Uriely, 2005; Rojas \& Camarero, 2008; Small, Darcy, \& Packer, 2012). There has also been greater interest on the practitioner side as destinations such as Canada and Australia are now emphasizing experiences rather specific tourism sites or products. The Signature Experiences Collection ${ }^{\circledR}$ developed by the Canadian Tourism Commission is a good example of this new thrust (Canadian Tourism Commission, 2012).

Uriely (2005) advocated a postmodernist conceptualization of tourist experiences and identified four related conceptual developments; (1) de-differentiation of everyday life and touristic experiences; (2) a shift from generalizing to pluralizing conceptualizations; (3) a transformed focus from the toured objectives to the tourist subjective negotiation of meanings; and (4) a transformation and a movement from contradictory and decisive statements to relative and complementary interpretations. Some of his propositions were that tourist experiences are very varied (pluralistic) and not uniform for everyone; the differences between everyday life and tourist experiences are becoming increasingly blurred; and that tourists attach their own 
subjective meanings to the experiences that they have.

Wildlife tourist experiences occur from interactions between humans and wildlife (Higham \& Shelton, 2011; Orams, 2002). In fact, the experiencing of wildlife has now become the business of wildlife tourism (Reynolds \& Braithwaite, 2011). This can be broadly defined as tourism undertaken to view or encounter wildlife (Newsome, Dowling, \& Moore, 2004). Wildlife tourism takes place in a range of settings in natural or artificial environments, where animals are free or captive, and where visitors can interact closely with the animals or merely watch from a distance (Higginbottom, 2004; Newsome et al., 2004; Rodger et al., 2007). Wildlife tourism experiences provide opportunities to observe and interact with animals that may be endangered, threatened or rare. They are being offered in an increasing number of destinations worldwide (Cousins, 2007; Orams, 2002; Woods \& Moscardo, 2003).

Reynolds \& Braithwaite (2001) developed a conceptual framework for wildlife tourism. For the richness and intensity of the wildlife tourism experience, six intrinsic quality factors were suggested by the two authors. Four of these quality factors were said to be present in all tourist experiences (authenticity; intensity; uniqueness; and duration). The other two quality factors were specific to wildlife tourism experiences; species popularity (e.g., physical attractiveness, size, danger, etc.) and species status (rarity and endangered status of animals).

Orams (2002) analyzed what attracted people to want wildlife tourism experiences and concluded that the decreasing number of opportunities to interact with nature was one of the important reasons.

Higham \& Carr (2003) developed insights into tourist experiences by gathering their viewpoints regarding the sustainability of wildlife experiences. This research was based on 12 ecotourism operations in New Zealand providing wildlife tourism as either primary or secondary components of tourism experiences. The study used content analysis of the comments from 76 tourists that were interviewed.

Higginbottom (2004) developed a model of the interactions of the components in wildlife tourism experiences. At the core of this model were the tourist-wildlife encounters and the wildlife tourism product. She further identified three factors influencing the core model components; wildlife and habitats, tourists, and the operators/businesses and settings. The impacts resulting from the consumption of the core components of wildlife tourism experiences were defined as being the effects on the natural environment, tourists, tourism operators, host communities, and economic returns. The Reynolds \& Braithwaite (2001) and Higginbottom (2004) models provided a solid conceptual and theoretical platform for future research on wildlife tourism. There is, however, a need for more empirical research to test and refine these models.

Ballantyne, Packer, \& Hughes (2009) explored the perceptions, preferences and conservation awareness of tourists visiting the Mon Repos Conservation Park in Queensland, Australia. The findings suggested that wildlife tourism management practices that enlist tourists as conservation partners, communicate the reasons behind any constraints imposed, and present a consistent message regarding interactions with wildlife are likely to be successful in meeting the needs of tourists and the wildlife. 
Ballantyne, Packer, \& Falk (2011) used structural equation modelling to identify factors that best predicted the long-term impacts of wildlife tourism experiences. The objective was to investigate how visitors' entering attributes combined with specific aspects of the wildlife tourism experience to produce changes in visitors' environmental knowledge, attitudes, and engagement in environmentally sustainable practices.

Ballantyne, Packer, \& Sutherland (2011) examined participants' memories of wildlife tourism experiences and explored processes through which such experiences could lead to long-term changes in conservation behaviour. Qualitative analysis revealed four levels of visitor responses to experiences; what visitors actually saw and heard (sensory impressions); what they felt (emotional affinity); thought (reflective responses); and finally what they did about it (behavioural responses).

That there is a plurality of wildlife tourism experiences now available cannot be denied. Wildlife tourism experiences and tourist behaviours vary widely by country and depending on the species types. Several research studies on different species across many countries have been conducted, including penguin viewing on the Otago Peninsula of New Zealand (Schaenzel,1998); whale watching in Australia (Catlin \& Jones, 2010); sea turtles in Australia (Wilson \& Tisdell, 1999); stingrays in the Gulf of Mexico (Semeniuk, Bourgeon, Smith, \& Rothley, 2009); dolphin-watching (Orams, 2002; Constantine, Brunton, \& Dennis, 2004); Florida manatees (Sorice, Scott, \& Ditton, 2005); and wild monkeys in Japan (Knight, 2010).

Overall, there have been many valuable contributions to the research literature on wildlife tourism from 2001 to 2011 inclusive. However, the importance of these interactions to the tourism sector and their impacts on many species of wildlife is not completely comprehended. There is still a need for more empirical analyses especially on tourist experiences when encountering wildlife of specific species and in different settings. More in-depth analysis of tourist experiences is important for the sustainable development of wildlife tourism as well as helping to ease potential conflicts between economics and wildlife conservation. Exploring tourist preferences and response behaviours for specific destinations and for certain wildlife species will help with sustainable tourism development (Mazanec \& Strasser, 2007). Moreover, greater analysis of wildlife tourist experiences will provide useful guidelines for tourism management and marketing.

\section{Content analysis of wildlife tourist experiences}

Content analysis is a research method for making replicable and valid inferences from data to their context, with the purpose of providing knowledge, new insights, a representation of facts and a practical guide to action (Krippendorff, 1980). It was first used more than 200 years ago as a method for analyzing hymns, newspapers and magazines, political speeches, advertisements, etc. (Harwood \& Garry, 2003).

With the development of websites and then social network systems (SNSs), tourists have become more capable and willing to share their experiences with the digital world. This has become a rich information source for researchers to analyze 
tourist experiences. Several studies have investigated photographs or text from websites to analyze different aspects of tourism (e.g., Choi, Lehto, \& Morrison, 2007; O’Leary \& Deegan, 2005; Stepchenkova \& Morrison, 2006; Stepchenkova, Kirilenko, \& Morrison, 2009).

Researchers have begun to apply new research methodologies to the analysis of wildlife tourism experiences. Some of these have been quantitative approaches; for example, Ballantyne, Packer, and Falk (2011) used structural equation modelling (SEM) to identify factors predicting positive long-term learning and environmental behavioural changes. Others have applied qualitative research techniques. Ballantyne, Packer, \& Sutherland (2011) used qualitative analysis of tourist answers to open-ended interview questions to reveal four levels of visitor responses to experiences. But their qualitative analysis was based only on questionnaires. Higham \& Carr (2003) used observations of tourists and interviews to examine wildlife tourism in New Zealand. They identified eight important aspects of tourist experiences. Content analyses of relevant websites, national and regional tourism directories, guidebooks, and magazines were also used to supplement the researchers' conclusions.

To date, therefore, content analysis using information from websites or SNSs for research on wildlife tourism experiences has been limited or, as in the case of Higham \& Carr (2003), this information has been used in a supplementary fashion. However, this increasingly rich and readily available vein of text data can be mined for further exploration of wildlife tourism experiences.

\section{Research on giant pandas}

The giant panda (Ailuropoda melanoleuca) is the rarest member of the bear family and among the world's most threatened animals. They live in the bamboo forests of six isolated mountain ranges in south-western China (Reid, 1994). The third national giant panda investigation was completed in June 2004 and estimated there to be 1,590 pandas alive in the wild; the nursery population under 1.5 years old was not included. The total number has been increasing. In addition, the 2010 China giant panda breeding statistics estimated that there were 314 pandas in captivity worldwide, with 46 of these being overseas (around 15\% of the captive population).

The giant panda is a conservation-relevant endangered species and great strides have been made to conserve them. The Chinese Government by 2005 had established over 50 panda reserves covering more than 2.5 million acres - over 45 percent of remaining giant panda habitat - and protecting more than 60 percent of the population. A 2006 study via DNA analysis estimated that the panda population could be as high as 2,000 to 3,000. The Chinese Forestry Bureau in October 2011 initiated the fourth investigation on the wild panda population and distribution (China Forestry Bureau, 2012).

There is much research on giant panda biological characteristics (Li et al., 2010), reproduction and feeding (Wei, Feng, \& Hu, 1997), wild giant panda population monitoring protection (Wang \& Zhao, 2008), and ecotourism planning in giant panda 
reserves. China has implemented many efforts for giant panda conservation, but there is much less concern about the human needs for close interactions with giant pandas, especially after the Wenchuan earthquake. The giant panda habitat was among the worst hit areas in Sichuan. Significant ecological landscape was destroyed or adversely modified, and infrastructure that took a long time to develop was damaged.

The giant panda is featured in the logo of the World Wildlife Fund (WWF). WWF's "All Time Top 10 Species to See" ranks the giant panda as the top species in the world that people want to see (World Wildlife Fund, 2012). Moreover, tourism associated with giant pandas is certainly one of the most unique tourism products provided within China. The dilemma is how to make the giant panda conservation projects sustainable and, at the same time, to satisfy tourist needs for close interactions with giant pandas.

There have been fewer research studies examining wildlife tourism in Asia, especially in China which has rich wildlife resources (Higginbottom, 2004). In particular, there has been very little research on tourist experiences with wildlife encounters in China. The tourist experiences with giant pandas, ranked as the top animal to view in the world, have yet to be empirically analyzed.

\section{Study background and objectives}

\subsection{Study site}

The Chengdu Research Base of Giant Panda Breeding (CRBGPB) is located in the northeast of downtown Chengdu and covers an area of 36.5 hectares. CRBGPB is a non-profit organization engaged in wildlife research, captive breeding, conservation education, and educational tourism. It was founded in 1987 with six giant pandas rescued from the wild. By the end of 2011, it had succeeded in having 109 births and a total of 161 baby pandas. CRBGPB is different from normal zoos as its main function is for giant panda breeding research. It has made great progress as a giant panda breeding center by freezing semen as the way to breed. CRBGPB's facilities include a Tourist Services Center, Giant Panda Museum, Research Center, Panda Story Cinema, Red Panda Enclosures, Giant Panda Nursery, Giant Panda Cub Enclosure, Adult Panda Enclosure, No. 14 Enclosure, Sub-adult Panda Enclosure, Giant Panda Hospital, Giant Panda Kitchen, Swan Lake, and Restaurant (site map provided in Fig. 1). The goals of CRBGPB are to be a world-class research facility, conservation education center, and international educational tourism destination. As the following quotation from CRBGPB's official website indicates, the educational tourism mission is taken very seriously:

As a famous sightseeing destination and a window to the wild, we improved our service facilities for tourists. Our efforts have made the Panda Base attractive to foreign and domestic audiences. We will fully use the resource of our endangered animals to strengthen conservation education to the public, and develop the Panda Base to be a unique educational tourism destination 
(http://www.panda.org.cn/english/visit/l.htm).

[Insert Fig. 1 about here]

The reasons for selecting CRBGPB for this research study were three-fold: 1) it is ranked as the top among 126 attractions in Chengdu as reviewed by tourists on TripAdvisor.com. Additionally, CRBGPB has the most reviews by tourists on TripAdvisor.com for panda facilities; 2) CRBGPB attracts domestic and international tourists; and 3) CRBGPB has a large number of captive pandas. The research team attempted to obtain attendance figures for CRBGPB, but were told by management that these statistics were confidential. However, a search of other sources indicated that there were approximately 900,000 visitors to CRBGPB in 2009; approximately $40 \%$ from China and $60 \%$ from international origins.

The understanding of wildlife tourism experiences has become more complex with the larger spectrum of information sources and channels. The focus of this research study was on the features of giant panda experiences based upon reviews written in TripAdvisor.com. The text from published reviews of CRBGPB was analyzed through the text mining and expert judgment approaches to content analysis (Singh, Hu, \& Roehl, 2007). The four specific research objectives were to:

1. Describe the types of tourism experiences that people have when encountering and interacting with giant pandas.

2. Identify tourist motivations for wanting to see and interact with giant pandas.

3. Examine satisfaction with the quality of tourism experiences when encountering and interacting with giant pandas.

4. Pinpoint factors or features that influence wildlife tourism experiences in the context of captive giant pandas.

\subsection{Methodology}

\subsubsection{Collection of textual information}

The sample of websites was selected through an exhaustive search of website lists under the travel directories of Yahoo and Google from April 17 to April 23, 2012.

Thereafter, a number of websites including TripAdvisor; TravelPod; Trip Blog; Lvping, and Sina were searched with the keywords of Chengdu Research Base of Giant Panda Breeding. After reviewing the search results, three websites were given further consideration (TripAdvisor.com; TravelPod; and Lvping).

TripAdvisor.com: TripAdvisor, founded in February 2000, is a travel website that assists customers in gathering travel information, posting reviews and opinions of travel-related contents, and engaging in interactive travel forums. It is one of the world's largest social travel networks and has 75 million reviews posted on it (TripAdvisor.com, 2012). CRBGPB was the top-ranked of 126 attractions in Chengdu (as checked on August 7, 2012). At the time of completing the research study, there were 296 reviews of CRBGPB; 153 reviews in English written by 151 persons (two 
people each published two reviews). The other 143 reviews were in non-English languages including Chinese, Japanese, and French. The researchers retained only the 153 reviews in English comprising a total of 20,717 words.

TravelPod.com: TravelPod is an online service which allows users to create travel blogs and was founded in 1997. Membership reached 20,000 members by November, 2005 (PRWeb, 2005). Using the keywords for CRBGPB, there were 74 blogs, of which 73 were in English, with a total word count of 77,277. However, all of these blogs were not limited to CRBGPB with people discussing all of the details of their trips to China. Since the blogs were not constrained to the giant panda tourist experiences, this source of text was disqualified.

Lvping.com: The researchers also checked this website, which is like a Chinese version of TripAdvisor.com. There were 184 reviews on CRBGPB. Since these were all written in Chinese, it was decided not to consider them within this research study.

\subsubsection{Text frequency analysis}

The text data were content-analyzed using ROST CM6. This is a large, free social computing platform software developed by Professor Shen of Wuhan University in China. Its main function is to help people in the humanities to conduct Weibo chat analysis, by calculating frequency statistics of Chinese and English words, as well as performing clustering analysis and certain other functions. The research team applied ROST CM6 to conduct the word frequency analysis (Table 3).

Several preliminary steps were needed to achieve the best interpretable results from this text-mining analysis:

(1) Some words did not contribute to a meaningful interpretation of the results and were removed. Examples included words such as 'is', 'a', 'the', 'I' 'of ', ' to', 'in', 'and', 'you', and some others.

(2) Inconsistencies caused by singular and plural nouns were resolved, e.g., 'baby' and 'babies', 'photo' and 'photos', etc.

(3) Inconsistencies caused by different verb tenses were resolved. For example, 'see' 'seeing' became 'saw' and 'took' and 'taken' converted to 'take.'

(4) Avoiding separate counting where the spellings of attraction sites were inconsistent.

(5) Grouping of names that were comprised of two and more words into one, again to avoid separate counting.

(6) Grouping terms with similar meanings but where different words were used, e.g., 'photograph' to 'photo' and 'centre' to 'center.'

\subsubsection{Coding and analysis}

The qualitative research process now followed by the research team could be classified as thematic analysis. Braun and Clarke (2006) defined thematic analysis as "a method for identifying, analysing and reporting patterns (themes) within data. It 
minimally organizes and describes your data set in (rich) detail." For this purpose, NVivo 8, a qualitative analysis tool from QSR International was used, and it is based on the grounded theory methodology. One of NVivo's major advantages is in its strong coding (Code) function, but it has other useful functions such as Set, Query, Link, Model, and others. After the text was entered into the NVivo software, three steps were followed:

Descriptive coding or free codes. The main aim was to find the basic relative content, but not to explain it (King \& Horrocks, 2010). The coding was done line by line, so as not to miss any important information. To ensure the reliability and validity of the coding, two team members coded the text separately (Wan, 2002).

Double-checks were made through discussions of each coding result. Where there were disagreements that could not resolved, a third person was introduced into the discussion. At end of this first step, the free coding spectrum included 68 free codes and 765 references (Table 4).

Interpretive coding. The second step was to classify the free codes, mainly based the literature reference materials, continuously comparing and analyzing the connections among the codes. This step is mainly to derive interpretive meanings (King \& Horrocks, 2010: 154) and is of called level 2 coding.

Overarching themes. This step defined the overarching themes with the data set of tourist reviews of CRBGPB. These broader themes often cover many different cases and reveal the core concepts and elements of the research (King \& Horrocks, 2010: 158). Braun and Clark (2006) refer to this as a "define and refine" process. Each tentative theme was reviewed one by one, as were the raw word text, and free and interpretive codes associated with each theme.

\section{Research results and findings}

\subsection{Demographics and countries of origin}

The proportion of male tourists (55.9\%) was higher than female (44.1\%); although it should be mentioned that there were a significant number of missing values for the genders of the writers of reviews (Table 1). Some $71.3 \%$ of the tourists were aged from 25 to 49 . Another 20.8\% were 50-64 years old; those 18-24 and 65 and over both accounted for less than $5 \%$.

The 151 review writers were from many different countries. The nations with the highest numbers were USA (23.7\%), China (16.5\%), UK (15.8\%), and Australia $(15.1 \%)$. Singapore and Malaysia each represented less than $5 \%$, and there were reviews from 30 additional people from other countries.

\section{[Insert Table 1 about here]}

A total of 294 people rated CRBGPB on the five-level scale provided by TripAdvisor; excellent, very good, average, poor, and terrible. Some $95.3 \%$ rated CRBGPB as either excellent or very good, indicating a very high level of enjoyment and satisfaction (Table 2). Only two of 294 people gave CRBGPB a below-average 
rating. For clarity purposes, it should be mentioned that not all the people who provided ratings $(n=294)$ also wrote reviews $(n=151)$ on CRBGPB.

[Insert Table 2 about here]

Because of the limitations of the text source, being only from the TripAdvisor.com website, limited demographic and origin information was available on the respondents. Additionally, since many people's personal information was left blank, there were significant numbers of missing values.

Table 3 shows the word frequencies for the "cleaned" text data using ROST CM6. Not surprisingly, "pandas" $(\mathrm{n}=541)$ had the highest word frequency. "Saw" $(\mathrm{n}=171)$ ranked second; and "time" $(\mathrm{n}=77)$ and "Chengdu" ranked third and fourth respectively. This word frequency analysis provided the foundation for the coding in the thematic analysis.

\section{[Insert Table 3 about here]}

\subsection{Thematic analysis of text}

There were 765 reference points and 68 free codes. For the second step of interpretive coding, the 68 free codes were reduced to 18 interpretive codes. In the third step, these 18 codes were reduced to three overarching themes; tourist features $(n=416 ; 54.4 \%)$; setting features $(n=244 ; 31.9 \%)$; and giant panda features $(n=105$; $13.7 \%)$.

\section{[Insert Table 4 about here]}

\subsubsection{Tourist features}

Features of the tourists were the most discussed in the text data set, representing more than half of the reference points. The interpretive codes identified therein were tourist behaviours, motivations, preferences, visit times, trip experiences, fellow travellers, emotional affinity, and sensory impressions.

Tourist behaviours: The tourist behaviours at CRBGPB could be divided into three parts based on their interactions with giant pandas; seeing or watching; holding; and other personal interactions. For panda watching, most people said the most important factor influencing the quality of experiences was the time of visiting CRBGPB. "Try to get to the Panda Research Base as early as you can" was a clear recommendation. In the early morning around 8 o'clock, the pandas are active and it is a panda feeding time. Seeing the panda nursery was another highlight of tourist experiences. Here there are many baby pandas of different ages, including a 5-week-old cub in an incubator, and in a bassinet type of enclosure there was a two-month old and two four-month old twins. One comment was that, "I got to see a staff member hold one of the twins and feed her a bottle. It was one of the cutest things I have ever seen!"

Many people talked about holding giant pandas, comprising 51 reference points. 
Holding pandas was one of the hottest topics and most prized experiences that tourists shared with others and most of them highly recommended this activity. When talking about holding pandas, they always mentioned the price, which is a 1,000 RMB (approximately USD 160) donation for giant panda research. Many tourists understood this practice and supported its contribution to panda conservation; "admittedly you only get at the most five minutes each to sit/hold a panda but it is worth every penny, believe me." However, there were tourists mentioning that it was very expensive to hold a panda for only five minutes and others complained about the experience because they felt the area was poorly organized. Taking photos often occurred when holding pandas.

Besides holding pandas, tourists mentioned observing and learning about them, and engaging in the volunteer program, such as feeding pandas. The volunteer program was one of the most satisfying experiences at CRBGPB and it was highly recommended by the tourists that participated. They gave very detailed descriptions of their volunteering and considered it to be the best way to interact with wildlife. People signing up for this program can have one to four days of close contact with giant pandas. They clean cages, prepare food and feed pandas, as well as observing them as they go about their daily routines. Although less people engaged in the volunteer program than holding and watching pandas, they were very highly satisfied with their experiences. Besides spending at least a whole day with close interactions with pandas, the price of the panda volunteer program is very reasonable at $600 \mathrm{RMB}$ per day.

Tourist motivations: Much fewer talked about their motivations for visiting CRBGPB. In general, there were three different types of motivations; (1) they loved pandas or were huge panda fans, some mentioning that "it is a dream come true to come this place"; (2) some went just because they were in Chengdu and felt they were obliged to go since they were in the city; and (3) others went to escape the hustle and bustle of the city, or just to kill time when in Chengdu.

Tourist preferences: Some tourists expressed personal preferences while others did not. It might be thought that for those who did not, their preferences were reflected in their behaviours. However, this coding only focused on those who articulated preferences. There were differences in what people most preferred; some valued the proximity to pandas, while others thought panda behaviour was the real attraction. Still others were most highly impressed by the settings at CRBGBP.

Most tourists were excited when seeing active giant pandas and chose the early morning as the best visiting time, since this is the time period when the animals are most active. Many tourists preferred to take photos with giant pandas, either by getting up close to them or by paying to hold a panda.

Some people liked the panda nursery, while others considered the red pandas to be "the stars of the show." There was also significant discussion about the high quality of the settings at CRBGPB, with some reviewers praising the shuttle service and layout and facilities as being world-class. It was especially pleasing for some to see giant pandas up close in what resembled their natural habitat. There were even some tourists who gave high marks to the toilet facilities at CRBGPB. 
[Insert Fig. 2 about here]

\subsubsection{Giant panda features}

The three interpretive codes for this feature were the abundance of pandas, panda behaviour, and panda conservation (Table 4). Many tourists mentioned the behaviour of giant pandas and the large number of pandas at CRBGPB. Giant pandas spend most of the time eating and sleeping, and they are only active in the morning and at feeding times. Giant pandas spend more than 13 hours a day eating bamboo and a mature panda can consume about 20 kilograms of bamboo each day. So for many tourists, the view of pandas was while they were eating. Apart from eating, pandas spend much time sleeping and they can even sleep in trees.

Some people were fortunate to witness more active panda behaviour. They reported that it was fascinating to see young pandas fighting with each other. Others observed active adult pandas; "Meanwhile a parent was patrolling and play fighting with some of the young. This is what I came for! It was great to see." Overall, the more active were the pandas, the greater was the satisfaction felt by tourists.

The CRBPBG is a unique place due to its abundance of giant pandas. Given its status as an endangered species, it is a very remarkable situation that tourists can encounter a significant proportion of the world's total giant panda population at one Research Base in Chengdu. CRBGPB started with just six giant pandas and now it has more than 100. Additionally, CRBGPB has giant pandas of all different ages. Other species of panda such as the red panda are also on display.

Giant pandas are a "living fossil" of ecosystem protection. Since the ancient era of the apes, there were giant pandas and they are still alive today. Therefore, the giant panda is a symbol of wildlife conservation and biological diversity. However, there remains a real urgency to do more for giant panda conservation. Many tourists really cared about panda conservation conditions and the project at CRBGPB. Thus, their survival status and what was being done to make them prosper were other significant attractions for certain tourists; "The pandas have big areas and it is not a zoo at all! The pandas in the centre are well kept and protected. The pandas are well looked after here and the carers really take care of them."

\subsubsection{Setting features}

There were several reviewers describing CRBGPB as a zoo; "though they are doing a great job breeding pandas and securing their survival and all, but it's kind of boring and looks like any other specialized zoo. The Panda breeding center is done in typical Chinese government style. In that, is has the potential to be something very special; however the PRC has institutionalized it." However, there were others who disagreed and thought the pandas had large areas and it was not a zoo at all.

Regarding transportation to CRBGPB, the reviews mentioned three different ways, such as taking taxis, buses, and tour coaches or vans. The internal transport within CRBGPB is via shuttle bus or tram and only costs 10 RMB.

Most reviews depicted CRBGPB as "quite clean and pleasant to walk around" 
and as being "large and well maintained and picturesque, full of trees."

For the facilities, many mentioned the panda museum, restaurant, Swan Lake, tourist center, antenatal clinic, toilets, shuttle service, gift shop, and movie theatre. Many judged CRBGPB to be, "A world class facility for pandas."

On the negative side, some noted there was no ATM in the park, which was not convenient if you wanted to pay in cash to hold a panda. Others commented that "the maps of the park were less than accurate."

Staff behavior and staff service were two other interpretive codes for this feature. There were comments about staff service, mentioning that staff members were very friendly, could communicate in English, and they cared most about the giant pandas; "The staff care more about their few precious bears, than all the tourists put together."

\section{[Insert Fig. 3 about here]}

\section{Discussion}

The types of experiences that people had at CRBGPB were quite varied and, therefore, these research findings supported Uriely's (2004) idea of the pluralistic nature of tourist experiences. Tourist motivations for visiting CRBGPB were also diverse and the subjective interpretations of experiences were different from person to person. The giant panda has become a symbol of China, as well as representing wildlife conservation. Many people connect giant pandas with Sichuan Province and more specifically with the "hometown of pandas" in Chengdu. So, those visiting CRBGPB varied from the highly-motivated "panda fans" to the "accidental tourists" who were in Chengdu for others reasons, but since there were there already felt obliged to see the giant pandas.

Reynolds and Braithwaite (2001) identified six quality factors influencing satisfaction with wildlife tourism experiences: authenticity, intensity, uniqueness, duration, species popularity, and species status. Giant pandas are listed as one of the most endangered species in the world and they have become a symbol for all of the most important species to be protected. There are very few giant pandas in the wild and their habitats are difficult to physically negotiate. Encounters and interactions with giant pandas are only realistic where these animals are in a captive setting. Therefore, although not explicitly measured in this research study, the tourist experiences at CRBGPB seemed to very positive for all six of Reynolds \& Braithwaite's quality factors. Generally, tourists writing reviews expressed high satisfaction levels with CRBGPB and their encounters with giant and other pandas.

The factors or features influencing the wildlife tourism experiences at CRBGPB were the tourists, giant pandas, and the settings of the Research Base.

\section{Conclusions, contributions and management implications}

This analysis of tourists' written reviews of wildlife tourism experiences has shed light on encounters with giant pandas in a captive situation. The research was exploratory and was designed to identify types of experiences, tourist motivations, 
preferences and satisfaction levels, and factors or features affecting this specific case of wildlife tourism experiences.

Visitor-wildlife encounters comprise the core of wildlife tourism products (if a commercial operator is involved) or of wildlife tourism experiences (if not) (Higginbottom, 2004). For this research, the core of the wildlife tourism experience was to be in close proximity to giant pandas, which was consistent with the research findings for other species, such as whale watching and whale shark experiences (Catlin, \& Jones, 2010; Reynolds \& Braithwaite, 2001).

Much of the wildlife tourism experience research to date has been conceptual or theoretical in nature. This study makes a contribution by analyzing a real-life situation within Asia, addressing the call for further research by scholars such as Higginbottom (2004). Moreover, the specific destination and species combination was unique; giant pandas in Chengdu, Sichuan. The use of thematic analysis of text information derived from tourist reviews on a website was also a unique approach in the field of wildlife tourism experience research.

The findings suggest that to evoke powerful memories, enhance tourist experiences, and encourage people to adopt environmentally responsible behaviours after their visits, wildlife tourism managers and operators should:

- Expand voluntourism programs: Pay greater attention to the volunteer tourism (voluntourism) market, which is an increasingly popular option for travel (Bailey \& Russell, 2010). This type of experience allows tourists to have much closer encounters with animals. This tends to enhance tourists' experiences, heighten environmental awareness, and assist with wildlife conservation programs.

- Tighten the control and management of external services: For example, CRBGPB needs to pay more attention to the transportation access options to the Research Base, especially since some tourists complained about taxi "scammers." Although this is not part of the operation itself, this situation is greatly affecting the Research Base's image, in a negative way.

- Improve photo-taking arrangements and services: The taking of photos is very important in recording tourists' experiences and so the arrangements made for photography are critical. The photo-taking arrangements at CRBGPB are not ideal and the management needs to devote greater attention to this situation. Better arrangements for queuing are needed for taking photos with giant pandas. Additionally, having staff available to take photos for/of tourists is also desirable.

- Enhance environmental interpretation information and systems: For example, the high price for holding a panda needs to be more clearly explained, as some tourists thought the price was too high and a "waste of money."

- Add more tourist services: There is often a need to increase facilities and services for tourist services, e.g., at CRBGPB there is a need to add ATM services.

- Improve maps, directional and building signs: Several tourists at CRBGPB complained that its maps were not accurate, while others said that the 
entrances to buildings were not well marked, making it difficult to access them.

\section{Limitations}

This research study was not without limitations. It must be recognized that interactions with giant pandas in the wild might be significantly different from the captive situation herein described at CRBGPB. Moreover, this research only had a focus on one species, but other wildlife species still remain to be studied in Asia and worldwide.

The results were based only upon tourists' reviews published on the TripAdvisor.com website. TripAdvisor is undoubtedly a valuable source of information on tourist opinions and behaviours, but this information is not without its critics. Some believe that TripAdvisor reviews reveal people's true motivations, preferences, and behaviours. Others argue that the reviews may not be representative of all tourists' opinions and also that "false reviews" are often posted.

Due to data limitations, this research did not examine the relationships among tourist characteristics and their experiences, preferences, and motivations. The methodology used was qualitative and not quantitative, and it was definitely exploratory in nature. Future research on encounters and interactions with giant pandas should use quantitative techniques along with other forms of qualitative analysis (e.g., individual in-depth interviews, focus groups, etc.).

Future researchers should consider invoking theories that may more fully explain tourist experiences and behaviours at sites such as CRBGPB. For example, involvement theory has been extensively applied in tourism research (Brey \& Lehto, 2007) and might be very relevant in this particular context. For example, those who signed up for the volunteer program at CRBGPB may be the most highly involved; while the "accidental tourists" may have the lowest involvement levels.

\section{References}

Bailey, A. W., \& Russell, K. C. (2010). Predictors of interpersonal growth in volunteer tourism. Leisure Sciences, 32(4): 352-368.

Ballantyne, R., Packer, J., \& Hughes, K. (2009). Tourists' support for conservation messages and sustainable management practices in wildlife tourism experiences. Tourism Management, 30(5): 658-664.

Ballantyne, R., Packer, J., \& Falk, J. (2011). Visitors' learning for environmental sustainability: Testing short- and long-term impacts of wildlife tourism experiences using structural equation modelling. Tourism Management, 32(6): 1243-1252.

Ballantyne, R., Packer, J., \& Sutherland, L. A. (2011). Visitors' memories of wildlife tourism: Implications for the design of powerful interpretive experiences. Tourism Management, 32(4): 770-779.

Braun, V., \& Clarke, V. (2006). Using thematic analysis in psychology. Qualitative Research in Psychology, 3(2): 77-101.

Brey, E. T., \& Lehto, X. Y. (2007). The relationship between daily and vacation 
activities. Annals of Tourism Research, 34(1): 160-180.

Briggs, H. (2006). Hope for the future of giant panda. BBC News, June 20.

Canadian Tourism Commission. (2012). Signature Experiences Collection ${ }$. http://en-corporate.canada.travel/resources-industry/signature_experiences_collect ion/?sc_cid=corpdomain38, accessed August 9, 2012.

Catlin, J., \& Jones, R. (2010). Whale shark tourism at Ningaloo Marine Park: A longitudinal study of wildlife tourism.Tourism Management, 31(3): 386-394.

Chengdu Research Base of Giant Panda Breeding. (2012). Educational Tourism Center - Visitor Education. http://www.panda.org.cn/english/visit/1.htm.

Choi, S., Lehto, X. Y., \& Morrison, A. M. (2007). Destination image representation on the web: Content analysis of Macau travel related websites. Tourism Management, 28(3): 118-129.

Constantine, R., Brunton, D. H., \& Dennis, T. (2004). Dolphin-watching tour boats change bottlenose dolphin (Tursiops truncatus) behaviour. Biological Conservation, 117(3): 299-307.

Cousins, J. A. (2007). The role of UK-based conservation tourism operators. Tourism Management, 28(4):1020-1030.

Curtin, S. (2010). Managing the wildlife tourism experience: The importance of tour leaders international journal of tourism research. International Journal of Tourism Research,12(3): 219-236.

Duffus, D. A., \& Dearden, P. (1990). Non-consumptive wildlife oriented recreation, a conceptual framework. Biological Conservation, 53(2): 213-231.

Forestry Bureau of China. (2012). http://www.forestry.gov.cn/portal/lxh/s/1405/content-129336.html, accessed August 9, 2012.

Green, R. J., \& Higginbottom, K. (2001). Negative effects of wildlife tourism on wildlife. Wildlife Tourism Research Report no. 5, Status assessment of wildlife tourism in Australia series. Gold Coast, Queensland: CRC for Sustainable Tourism.

Harwood T. G., \& Garry T. (2003) An overview of content analysis. The Marketing Review, 3, 479-498.

Higginbottom, K. (2004). Wildlife tourism: Impacts, management and planning. Gold Coast: Common Ground Publishing. CRC for Sustainable Tourism.

Higginbottom, K. (2004). Wildlife tourism: an introduction. In K. Higginbottom (Ed.), Wildlife tourism: Impacts, management and Planning. Common Ground Publishing in Association with the Cooperative Research Centre for Sustainable Tourism (pp. 1-14). Altona, Victoria: Australia.

Higham, J. E. S., \& Carr, A. M.(2003) Sustainable Wildlife Tourism in New Zealand: An Analysis of Visitor Experiences. Human Dimensions of Wildlife, 8(1): 25-36.

Higham, J. E. S., \& Shelton, E. J. (2011).Tourism and wildlife habituation: Reduced population fitness or cessation of impact? Tourism Management, 32(6):1290-1298.

Johannesen, A. B., \& Skonhoft, A. (2005). Tourism, poaching and wildlife conservation: What can integrated conservation and development projects 
accomplish? Resource and Energy Economics, 27(3): 208-226.

Krippendorff, K. (1980). Content analysis: An introduction to its methodology. Sage Publications, Newbury Park.

King, N., \& Horrocks, C. (2010). Interviews in qualitative research. London: Sage Publications, Ltd.

Knight, J. (2010).The ready-to-view wild monkey. Annals of Tourism Research, 37(3): 744-762.

Li, R., et al. (2010). The sequence and de novo assembly of the giant panda genome. Nature, 463, 311-317.

Lee, W. H., \& Moscardo, G. (2005). Understanding the impact of ecotourism resort experiences on tourists' environmental attitudes and behavioral intentions. Journal of Sustainable Tourism, 13(6), 546-565.

Mazanec, J. A., \& Strasser, H. (2007). Perceptions-based analysis of tourism products and service providers. Journal of Travel Research, 45(4): 387-401.

Newsome, D., Dowling, R. K., \& Moore, S. A. (2004). Wildlife tourism. Clevedon UK: Channel View Publications.

O' Leary, S., \& Deegan, J. (2005). Ireland's image as a tourism destination in France: Attribute importance and performance. Journal of Travel Research, 43(3), 247-256.

Orams M. B. (2000).Tourists getting close to whales, is it what whale-watching is all about? Tourism Management, 21(6): 561-569.

Orams, M. B. (2002). Feeding wildlife as a tourism attraction: A review of issues and impacts. Tourism Management, 23(3): 281-293.

Pike, S., \& Ryan, C. (2004). Destination positioning analysis through a comparison of cognitive, affective, and cognitive perceptions. Journal of Travel Research, 42(4): 333-342.

PRWeb. (2005). TravelPod.com tops 20,000 members. http://www.prweb.com/releases/2005/11/prweb306152.htm, Retrieved August 8, 2012.

Quan, S., \& Wang, N. (2004). Towards a structural model of the tourist experience: An illustration from food experiences in tourism. Tourism Management, 25(3): 297-305.

Reid, D. G., (1994). The focus and role of biological research in giant panda conservation. Bears: Their Biology and Management, 9(1), 23-33.

Reynolds, P. C., \& Braithwaite, D. (2001). Towards a conceptual framework for wildlife tourism. Tourism Management, 22(1): 31-42.

Rodger, K., Moore, S. A., \& Newsome, D. (2007). Wildlife tours in Australia: Characteristics, the place of science and sustainable futures. Journal of Sustainable Tourism, 15(2): 160-179.

Rodger, K., \& Moore, S. A.(2004). Bringing science to wildlife tourism: The influence of managers'and scientists' perceptions. Journal of Ecotourism, 3(1):1-19.

Rodger, K., Moore, S. A., \& Newsome, D. (2009). Wildlife tourism, science and actor network theory. Annals of Tourism Research, 36(4): 645-666. 
Rojas, C., \& Camarero, C. (2008).Visitors' experience, mood and satisfaction in a heritage context: Evidence from an interpretation center. Tourism Management, 29(3): 525-537.

Ryan.C. (2002). The tourist experience, $2^{\text {nd }}$ Ed. London: Continuum.

Schaenzel, H. (1998). The effectiveness of environmental interpretation: Understanding the values gained from wildlife viewing tourism experiences. Environmental Perspectives, 21, 10-13.

Semeniuk, C. A. D., Bourgeon, S., Smith, S.L., \& Rothley, K. D. (2009). Hematological differences between stingrays at tourist and non-visited sites suggest physiological costs of wildlife tourism. Biological Conservation, 142(8): 1818-1829.

Semeniuk, C. A. D., Haider, W., Cooper, A., \& Rothley, K.D. (2010). A linked model of animal ecology and human behavior for the management of wildlife tourism. Ecological Modeling, 221(22): 2699-2713.

Shackley, M. (1996). Wildlife tourism. UK: Thompson Business Press.

Singh, N., Hu, C., \& Roehl, W. S. (2007). Text mining a decade of progress in hospitality human resource management research: Identifying emerging thematic development. International Journal of Hospitality Management, 26, 131-147.

Small, J., Darcy, S., \& Packer, T. (2012). The embodied tourist experiences of people with vision impairment: Management implications beyond the visual gaze. Tourism Management, 33(4): 941-950.

Smith, L. D. G., Ham, S. H., \& Weiler, B. V. (2011). The impacts of profound wildlife experiences. Anthrozoos, 24(1): 51-64.

Sorice, M. G., Shafer, C. S., \& Ditton, R. B.(2005). Managing endangered species within the use-preservation paradox: The Florida Manatee (Trichechus manatus latirostris) as a tourism attraction. Environmental Management, 37(1): 69-83.

Stepchenkova, S., \& Morrison, A. M. (2006). The destination image of Russia: From the online induced perspective. Tourism Management, 27(5): 943-956.

Stepchenkova, S., Kirilenko, A. P., \& Morrison, A. M. (2009). Facilitating content analysis in tourism research. Journal of Travel Research, 47(4): 454-469.

TripAdvisor.com. (2012). About TripAdvisor. http://www.tripadvisor.com/pages/about_us.html, accessed August 9, 2012.

Uriely,N. (2005). The tourist experience: Conceptual developments. Annals of Tourism Research, 32(1): 199-216.

Wan, C. S. (2002). The web sites of international tourist hotels and tour wholesales in Taiwan. Tourism Management, 23(2):155-160.

Wang, Y. \& Zhao, P. (2008). Advances in the monitoring of Giant Panda based on GIS in China. Journal of Northwest Forestry University, 23(4):136-140

Wei, F., Feng, Z., \& Hu, J. (1997). Population viability analysis computer model of Giant Panda population in Wuyipeng, Wolong Natural Reserve, China. Bears: Their Biology and Management, 9(2):19-23.

Wilson, C., \& Tisdell, C. (2001). Sea turtles as a non-consumptive tourism resource especially in Australia.Tourism Management, 22(3): 279-288.

Woods, B., \& Moscardo, G. (2003). Enhancing wildlife education through 
mindfulness. Australian Journal of Environmental Education, 19, 97-108.

World Wildlife Fund. 2012. The "All Time" Top 10 - As voted for by YOU! The "All Time" Top 10 - As voted for by YOU!

http://wwf.panda.org/about_our_earth/teacher_resources/best_place_species/allti me top10/, accessed August 9, 2012. 
Table 1. Demographics and Country of Origins of Giant Panda Tourists

\begin{tabular}{|c|c|c|}
\hline \multirow{2}{*}{$\begin{array}{l}\text { Demographics and } \\
\text { Origins }\end{array}$} & \multicolumn{2}{|c|}{ Tourists $(\mathrm{n}=151)$} \\
\hline & Frequency & Percentage $(\%)$ \\
\hline \multicolumn{3}{|l|}{$\begin{array}{l}\text { Gender }(\mathrm{n}=102 \\
\text { missing values }=49)\end{array}$} \\
\hline Male & 57 & $55.9 \%$ \\
\hline Female & 45 & $44.1 \%$ \\
\hline \multicolumn{3}{|l|}{$\begin{array}{l}\text { Age }(n=101 ; \text { missing } \\
\text { values }=50)\end{array}$} \\
\hline $18-24$ & 5 & $3.0 \%$ \\
\hline $25-34$ & 33 & $32.7 \%$ \\
\hline $35-49$ & 39 & $38.6 \%$ \\
\hline $50-64$ & 21 & $20.8 \%$ \\
\hline Over 65 & 3 & $1.9 \%$ \\
\hline \multicolumn{3}{|l|}{$\begin{array}{l}\text { Country }(\mathrm{n}=139 \\
\text { missing values }=12)\end{array}$} \\
\hline USA & 33 & $23.7 \%$ \\
\hline China & 23 & $16.5 \%$ \\
\hline UK & 22 & $15.8 \%$ \\
\hline Australia & $\begin{array}{c}21 \\
5\end{array}$ & $15.1 \%$ \\
\hline Singapore & $\begin{array}{l}5 \\
5\end{array}$ & $3.6 \%$ \\
\hline Malaysia & $\begin{array}{c}5 \\
30\end{array}$ & $\begin{array}{l}3.0 \% \\
216 \%\end{array}$ \\
\hline Others & & \\
\hline
\end{tabular}

Source: Table based on the data collected from TripAdvisor.com and drawn by research team 
Table 2. Tourist Ratings of Chengdu Research Base of Giant Panda Breeding

\begin{tabular}{|l|c|c|}
\hline Ratings & Frequencies $(\mathrm{n}=294)$ & Percentages $(\%)$ \\
\hline Excellent & 194 & $66.0 \%$ \\
\hline Very good & 86 & $29.3 \%$ \\
\hline Average & 12 & $4.1 \%$ \\
\hline Poor & 1 & $0.3 \%$ \\
\hline Terrible & 1 & $0.3 \%$ \\
\hline
\end{tabular}

Source: Table based on the data collected from TripAdvisor.com and drawn by research team 
Table 3. Word frequency statistics

\begin{tabular}{|c|c|c|}
\hline Rank & Word & Frequency \\
\hline 1. & Pandas & 541 \\
\hline 2. & Saw & 171 \\
\hline 3. & Time & 77 \\
\hline 4. & Chengdu & 73 \\
\hline 5. & Center & 65 \\
\hline 6. & Park & 65 \\
\hline 7. & Great & 64 \\
\hline 8. & RMB & 64 \\
\hline 9. & Taken & 64 \\
\hline 10. & Place & 63 \\
\hline 11. & Baby & 59 \\
\hline 12. & Photo & 59 \\
\hline 13. & Well & 56 \\
\hline 14. & Visit & 56 \\
\hline 15. & Take & 54 \\
\hline 16. & Worth & 52 \\
\hline 17. & Base & 51 \\
\hline 18. & Enclosure & 49 \\
\hline 19. & Walking & 45 \\
\hline 20. & Morning & 43 \\
\hline 21. & Hours & 43 \\
\hline 22. & Research & 41 \\
\hline 23. & Early & 40 \\
\hline 24. & Tour & 39 \\
\hline 25. & Trip & 44 \\
\hline 26. & Good & 39 \\
\hline 27. & Giant & 37 \\
\hline 28. & Hold & 37 \\
\hline 29. & Cubs & 41 \\
\hline 30. & Tourists & 37 \\
\hline
\end{tabular}

Source: Based upon statistical frequency data from ROST CM6 
Table 4. The coding spectrum in the thematic analysis

\begin{tabular}{|c|c|c|c|c|}
\hline $\begin{array}{l}\text { Overarching } \\
\text { Themes }\end{array}$ & Interpretive Codes & Free codes & Frequencies & Percents \\
\hline \multirow[t]{3}{*}{$\begin{array}{l}\text { Panda } \\
\text { Features }\end{array}$} & $\begin{array}{l}\text { Abundance of } \\
\text { pandas }\end{array}$ & $\begin{array}{l}\text { Abundance of pandas; amount of } \\
\text { pandas; red panda }\end{array}$ & 42 & $5.5 \%$ \\
\hline & Panda behaviour & Panda behaviour; panda feeding & 42 & $5.5 \%$ \\
\hline & $\begin{array}{l}\text { Panda } \\
\text { conservation }\end{array}$ & $\begin{array}{l}\text { Habitat; living situation of pandas; } \\
\text { panda conservation; panda living } \\
\text { situation; physiological knowledge } \\
\text { of giant panda; reasons for scarcity; } \\
\text { the functions of the center; scarcity }\end{array}$ & 21 & $2.8 \%$ \\
\hline \multirow[t]{7}{*}{$\begin{array}{l}\text { Setting } \\
\text { Features }\end{array}$} & $\begin{array}{l}\text { Destination } \\
\text { attributes }\end{array}$ & $\begin{array}{l}\text { Chinese culture; climate; local } \\
\text { people; location; weather }\end{array}$ & 17 & $2.2 \%$ \\
\hline & $\begin{array}{l}\text { Facilities in the } \\
\text { park }\end{array}$ & $\begin{array}{l}\text { Facilities; panda movie; } \\
\text { museum; signage; souvenirs }\end{array}$ & 60 & $7.8 \%$ \\
\hline & Park environment & $\begin{array}{l}\text { Food; guide; panda card; park area; } \\
\text { park environment; park } \\
\text { management; queue for holding } \\
\text { pandas; tour guide }\end{array}$ & 85 & $11.1 \%$ \\
\hline & Transportation & $\begin{array}{l}\text { Take taxi; transportation in park; } \\
\text { transportation to the park }\end{array}$ & 22 & $2.9 \%$ \\
\hline & Price & Price & 55 & $7.2 \%$ \\
\hline & Staff behavior & Treatment of animals & 4 & $0.5 \%$ \\
\hline & Staff service & Staff service & 1 & $0.1 \%$ \\
\hline \multirow[t]{6}{*}{$\begin{array}{l}\text { Tourist } \\
\text { Features }\end{array}$} & Emotional affinity & $\begin{array}{l}\text { Description of panda; emotional } \\
\text { affinity }\end{array}$ & 42 & $5.5 \%$ \\
\hline & Fellow travelers & $\begin{array}{l}\text { Book a tour; children visitors; } \\
\text { fellow travellers }\end{array}$ & 10 & $1.3 \%$ \\
\hline & $\begin{array}{l}\text { Sensory } \\
\text { impressions }\end{array}$ & $\begin{array}{l}\text { Compare to zoo; fun place; } \\
\text { perception of park; perception of } \\
\text { trip }\end{array}$ & 83 & $10.9 \%$ \\
\hline & Tourist behaviours & $\begin{array}{l}\text { Behaviour after the trip; buy } \\
\text { souvenirs; feed panda; hold panda; } \\
\text { learn about panda; length of stay; } \\
\text { observe panda; see nursery; take } \\
\text { photos; tourist behaviour; volunteer } \\
\text { program }\end{array}$ & 147 & $19.2 \%$ \\
\hline & $\begin{array}{l}\text { Tourist } \\
\text { motivations }\end{array}$ & Tourist motivation & 10 & $1.3 \%$ \\
\hline & $\begin{array}{l}\text { Tourist } \\
\text { preferences }\end{array}$ & Tourist preferences & 22 & $2.9 \%$ \\
\hline
\end{tabular}




\begin{tabular}{|l|l|l|c|c|}
\hline & Trip experiences & $\begin{array}{l}\text { Efficient way for panda time; } \\
\text { previous experience; revisit route } \\
\text { of the trip }\end{array}$ & 8 & $1.1 \%$ \\
\cline { 2 - 5 } & Visit time & Visit time & 94 & $12.3 \%$ \\
\hline
\end{tabular}




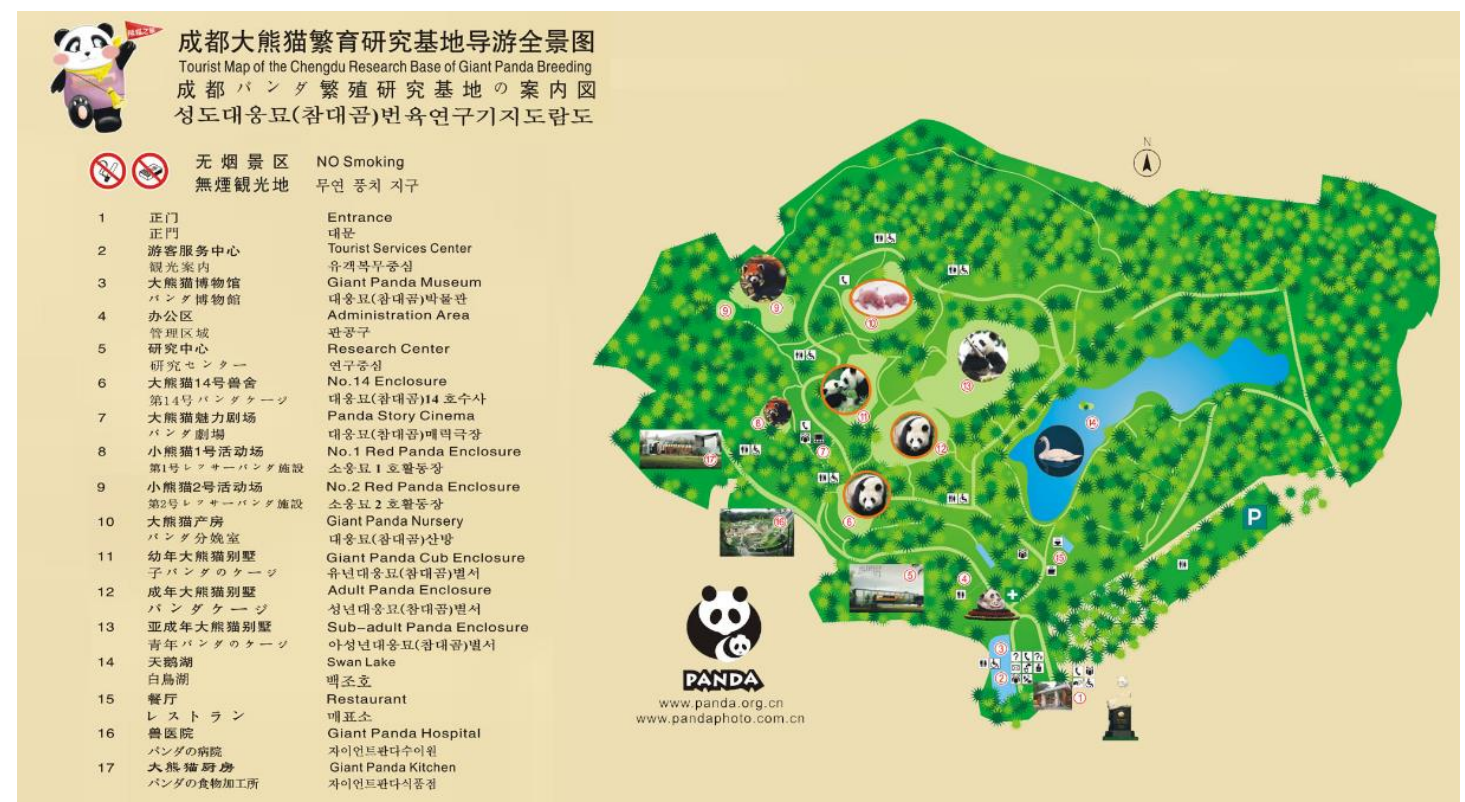

Fig 1. Map of Chengdu Research Base of Giant Panda Breeding

Source: Chengdu Research Base of Giant Panda Breeding 


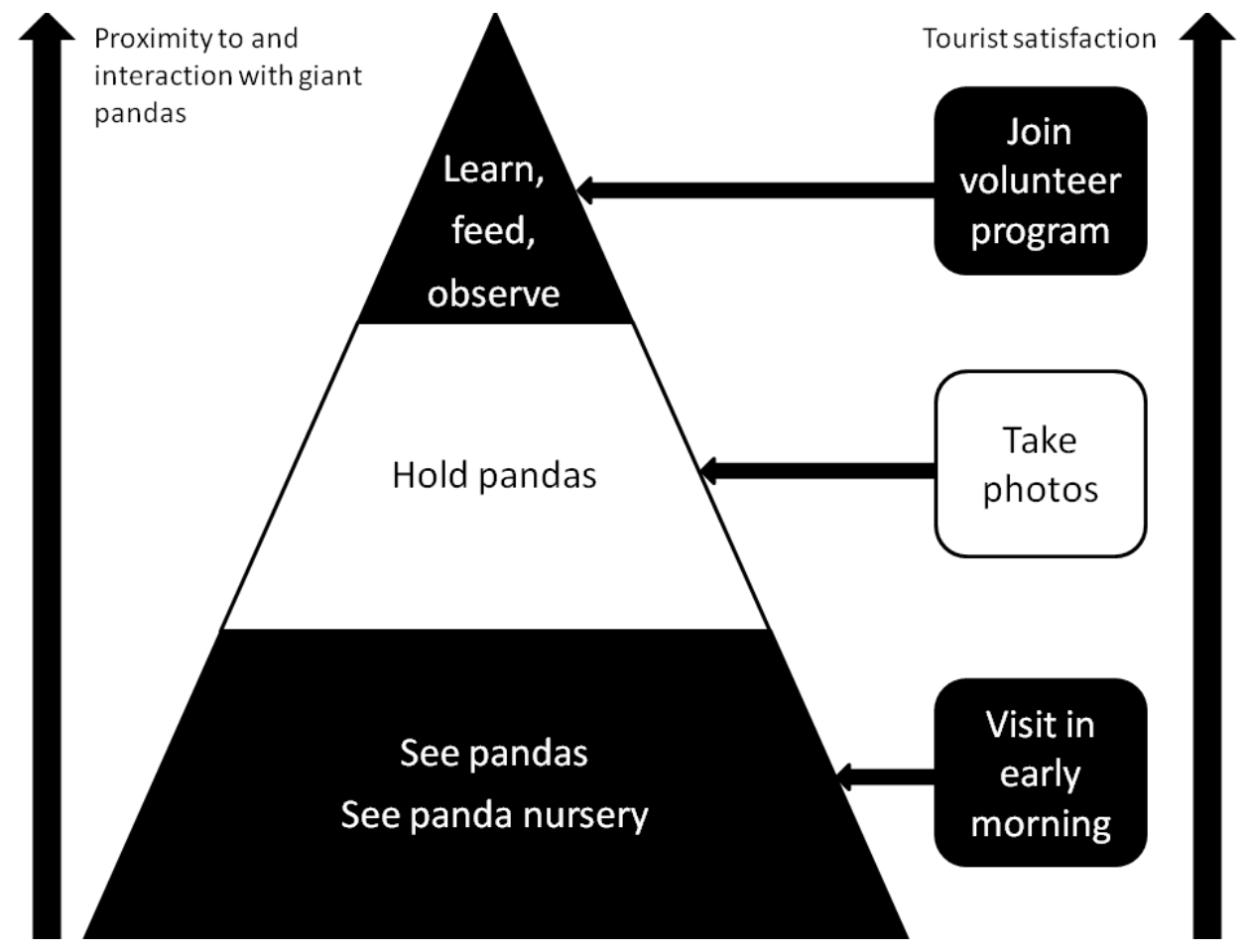

Fig. 2. Tourist response behaviours compared with satisfaction and proximity/interaction with giant pandas

Source: Drawn by research team 


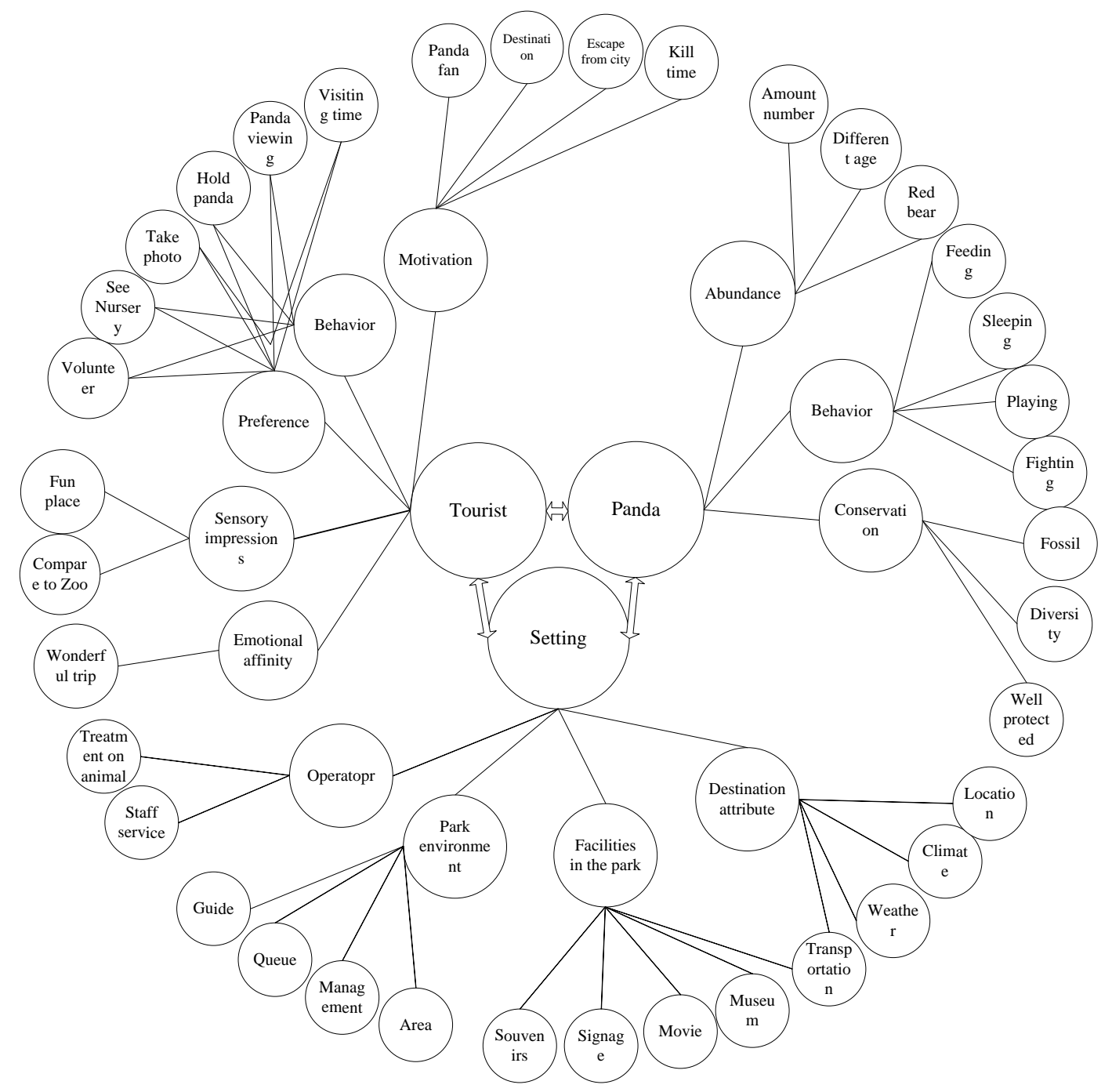

Fig 3. Features of the wildlife tourism experience at the Chengdu Research Base of Giant Panda Breeding

Source: Drawn by the research team 